\title{
Intra-annual density fluctuations (IADFs) in Pinus nigra (J. F. Arnold) at high-elevation in the central Apennines (Italy)
}

\author{
Alma Piermattei $^{1}$ (1) $\cdot$ Filipe Campelo $^{2} \cdot$ Ulf Büntgen $^{1,3,4,5} \cdot$ Alan Crivellaro $^{1} \cdot$ Matteo Garbarino $^{6} \cdot$ Carlo Urbinati $^{7}$
}

Received: 26 May 2019 / Accepted: 13 January 2020 / Published online: 27 January 2020

(c) The Author(s) 2020

\begin{abstract}
Although wood anatomical features can provide yearly resolved climatic information at sub-seasonal resolution, the occurrence of intra-annual density fluctuations (IADFs) might be triggered by several abiotic factors under different ecological settings. Here, we use information on cambial age and tree-ring width to standardize the frequency of IADFs in European black pines from three different mountain slopes in the central Apennines (Italy). At each site, we sampled isolated 15-30year pioneer pines above the forest limit, as well as close-grown 40-60-year planted pines at the forest limit. Mainly restricted to the latewood of both pioneer and planted trees, the occurrence of IADFs reveals a significant positive relationship with cambial age and ring width. Although the standardized IADFs are well synchronized between the planted and pioneer pines, the frequency of IADFs in narrow rings was higher in the pioneer pines. Drought conditions in July and August are responsible for the highest IADFs frequency in planted and pioneer pines, respectively. Our study underlines the value of IADFs to obtain a more nuanced understanding of the climatic drivers of wood formation at the intra-annual scale.
\end{abstract}

Keywords European black pine · Anthropogenic forest limit · Pioneer vs planted $\cdot$ Standardization $\cdot$ Weibull and Chapman functions

Communicated by Gratani.

Electronic supplementary material The online version of this article (https://doi.org/10.1007/s00468-020-01956-1) contains supplementary material, which is available to authorized users.

Alma Piermattei

alma.piermattei@geog.cam.ac.uk

1 Department of Geography, University of Cambridge, Downing Place, Cambridge CB2 3EN, UK

2 Department of Life Sciences, CFE - Centre for Functional Ecology - Science for People and the Planet, University of Coimbra, 3000-456 Coimbra, Portugal

3 Dendro Science Group, Swiss Federal Research Institute - WSL, Zürcherstrasse 111, 8903 Birmensdorf, Switzerland

4 CzechGlobe, Global Change Research Institute CAS, Bělidla 986/4a, 60300 Brno, Czech Republic

5 Department of Geography, Faculty of Science, Masaryk University, Kotlářská 2, 60200 Brno, Czech Republic

6 Department DISAFA, Università degli Studi di Torino, Largo Braccini 2, 10095 Grugliasco, Italy

7 Department of Agricultural, Food and Environmental Sciences - D3A, Marche Polytechnic University, Via Brecce Bianche 12, 60131 Ancona, Italy

\section{Introduction}

Though tree-ring width records are among the most important and commonly used annually resolved climate proxies (Sheppard 2010), intra-ring wood anatomical traits, such as intra-annual density fluctuations (IADFs), resin canals density, and maximum wood density, can also provide useful climate-growth information, albeit at sub-seasonal resolution (De Luis et al. 2007; Esper et al. 2015; Björklund et al. 2017). However, it is not clearly understood, at the intraannual level, how the many climatic factors affecting wood formation operate at the anatomical level (Olano et al. 2012). Within the growing season, environmental and climatic variations set the pace of cambial activity and cell development, leading eventually to IADFs formation (e.g., Bogino et al. 2009; Battipaglia et al. 2016). The position of IADFs within a ring (e.g., in earlywood or in latewood) is also determined by the timing of the triggering factor (Campelo et al. 2007). Therefore, the study of IADFs can help to detect changes in cambial activity within the growing season (Campelo et al. 2007; Rozas et al. 2011; De Micco et al. 2014). However, the occurrence of IADFs is not straightforward, since their formation is not only climate driven, but also influenced by 
other factors, such as slope, aspect, tree species, tree status, tree age, and total ring width (Vieira et al. 2009; Campelo et al. 2013; Klisz et al. 2016; Zalloni et al. 2016; Campelo et al. 2018).

Recently, new analytical methods have been developed to disentangle IADFs triggering factors. Novak et al. (2013) assessed the IADF climatic signal in Pinus halepensis in Spain applying a three-parameter Weibull function to remove the effect of cambial age on IADFs frequency. Campelo et al. (2015) removed direct (indirect) ring-width (cambial age) effects from IADFs chronologies after standardizing with a Chapman function. Both methods increase or add new signals to IADFs chronologies by removing the effect of predisposing factors. For example, a negative effect of September temperature on IADF formation was detected only after removing the ring-width effect (Campelo et al. 2015).

In this study, we investigated tree-ring growth and IADFs occurrence on European black pine (Pinus nigra J. F. Arnold) growing at high altitude in three sites at the central Apennines, Italy. In addition, we proposed a revised method to remove the tree-ring width and age effects from IADFs chronologies by adjusting a Chapman or a Weibull functions.

At each site, we sampled planted pines (PLP) at the upper closed forest limit, and pioneer pines (PIP) occurring above the artificial upper forest line. PLP were planted in the 1950s, whereas the PIP represent natural regeneration 15-20 years after the planted pines reached maturity (Piermattei et al. 2014; Vitali et al. 2017). The planted pines are older, located at lower altitude, and grow in dense stands. In contrast, the pioneer pines are younger and mainly live as isolates. We tested the following two hypotheses: (1) the IADFs frequency in pioneer pines is higher than in planted pines due to the more limiting growing conditions and to the lower cambial ages, and (2) the IADFs frequency is synchronized among the three sites for PIP and PLP, suggesting a common climatic driver.

\section{Material and methods}

\section{Study sites}

The three sites are Mt. Vettore (VET), Mt. San Franco (SFR) and Mt. Ocre (OCR) in the central Apennines (Italy). They are located within the Sibillini Mts. National Park, Gran Sasso and Laga Mts. National Park, and Acquazzese Forest Natural Reserve, respectively (Fig. 1). All sites differ in their aspect, slope angle and altitude of the upper forest line (Table 1, Fig. 1). At all sites, we sampled PLP close to the upper edge of the forest limit. At VET and SFR, we sampled PIP along the entire ecotone above the forest line; whereas at
OCR we were limited to an altitudinal transect $200 \mathrm{~m}$ wide, extending to the mountain top, due to the higher density of pine cohorts. At all sites PIP are randomly distributed between 1600 and $2100 \mathrm{~m}$ a.s.l. (Piermattei et al. 2016).

\section{Tree-ring data analysis}

Dendrochronological sampling took place between 2009 and 2014 during which one basal increment core from each pioneer pine and two breast height cores from each planted tree were collected. All cores were mounted on wood supports and polished using sandpapers of a progressively finer grain (from 240 to 1000 grit) until tree-ring boundaries and cells were clearly visible under a binocular stereomicroscope. Tree-ring width was measured with the LINTAB device and TSAPWin software (Rinntech, Germany) to $0.01 \mathrm{~mm}$ precision. Cross-dating quality was checked visually and using COFECHA software (Holmes, 1983). The dating of each individual series was checked against a local master chronology and deleted from the dataset if the Pearson's correlation coefficient $(r)$, was less than 0.4 . For pioneer pines, only cores with more than 15 tree rings, no visible damage, and containing the pith were selected. For planted pines, the core with the highest number of tree-rings and containing the pith was used. PLP and PIP tree-ring width series were detrended using a 20-years smoothing spline with 50\% frequency cutoff, which isolated high-frequency variability, using the R packages detrende R (Campelo et al. 2012) and dplR (Bunn 2008). Autoregressive modelling was performed to remove the temporal autocorrelation. Finally, a biweight robust mean was computed to average the individual series and to produce standardized tree-ring width chronologies. For each PLP and PIP tree-ring width chronology, the mean sensitivity (MS), the first-order autocorrelation (AC1), the inter-series correlation (Rbar), and the expressed population signals (EPS, Wigley et al. 1984) were computed. Mean ring widths, MS and AC1 were calculated on the raw data, while Rbar and EPS were calculated on the indexed series. The Spearman's correlation $(\rho)$ between all PLP and PIP treering width chronologies, both between and within sites, was also calculated.

\section{Intra-annual density fluctuations}

To detect IADFs presence and type a stereomicroscope, with up to a $25 \times$ magnification, was used. IADFs were classified according to their positions within the tree ring. Type E IADFs are those characterized by latewood-like cells within the earlywood; type E+ within transition cells between earlywood and latewood; type $\mathrm{L}$ are those formed by earlywood-like cells within latewood, and type $\mathrm{L}+$ showing earlywood-like cells between the latewood and the earlywood of the following tree ring (Campelo et al. 2007). Since 


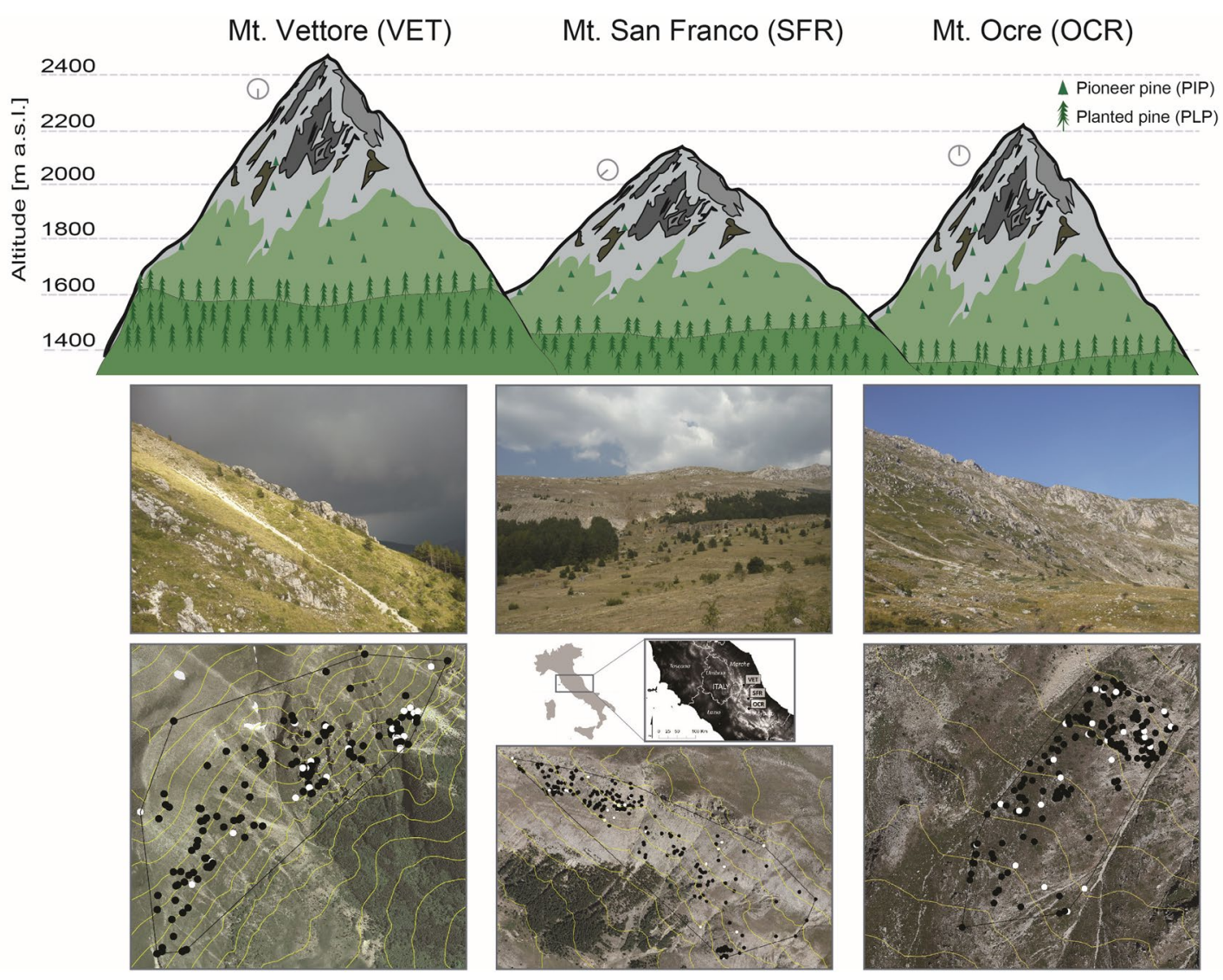

Fig. 1 Representation of the three study sites located in the central Apennines (Italy): Mt. Vettore (VET), Mt. San Franco (SFR), and Mt. Ocre (OCR). For each site, from top to bottom we provided: an altitude and aspect layout, a site overview, and the spatial distribution of all sampled trees over a 2010 orthophoto. In the orthophoto alti- tude contours are every $50 \mathrm{~m}$, black dots are the pioneer pines (PIP) sampled above the artificial pine plantation (PLP), and white dots the pioneer pines analysed for this study. In the orthophoto, the altitude increases across a bottom up direction
Table 1 Main features of the three study sites: VET (Mt. Vettore); SFR (Mt. San Franco); OCR (Mt. Ocre)

\begin{tabular}{|c|c|c|c|}
\hline & VET & SFR & OCR \\
\hline Geographic coordinates (Lat.; Long.) & $42^{\circ} 81^{\prime} \mathrm{N} ; 13^{\circ} 26^{\prime} \mathrm{E}$ & $42^{\circ} 45^{\prime} \mathrm{N} ; 13^{\circ} 38^{\prime} \mathrm{E}$ & $42^{\circ} 15^{\prime} \mathrm{N} ; 13^{\circ} 27^{\prime} \mathrm{E}$ \\
\hline Pine forest upper limit altitude (m a.s.l.) & 1600 & 1500 & 1350 \\
\hline $\begin{array}{l}\text { Altitude range of pioneer pines } \\
\text { encroachment ( } \mathrm{m} \text { a.s.l.) }\end{array}$ & $1610-2050$ & $1695-1930$ & $1635-1915$ \\
\hline Slope aspect & S-SE & W-SW & $\mathrm{N}-\mathrm{NE}$ \\
\hline Slope steepness (\%) & 35.8 & 31.7 & 33.3 \\
\hline
\end{tabular}

the occurrence of IADFs in the earlywood (E and E+) was very low, only the frequency of IADFs in the latewood zone ( $\mathrm{L}, \mathrm{L}+$ or both $\mathrm{LL}+$ ) was used. Because of their non-normal distribution, IADFs frequency cannot be used directly as a continuous variable in regression equations. Therefore, a binary dataset assigning the value 1 for presence or 0 for absence of IADFs in each tree ring in a core was built. There are different approaches to develop IADFs chronologies, and correcting the bias introduced by changing sample depth over time (Osborn et al. 1997), by cambial age (Novak et al.
2013), and by size (Campelo et al. 2015). To calculate the IADFs frequency through time, and with varying sample depth, the method of Osborn et al. (1997) was applied. The adjusted IADFs frequency was calculated as follows:

$f($ stabilized IADF frequency $)=F \times n^{0.5}$

where $F$ is the ratio of $N / n$, where $N$ is the number of trees possessing an IADF type in a given year, and $n$ is the total number of observed trees. However, to develop IADFs 
chronologies without the effect of age and size the method proposed by Campelo et al. (2015) was adapted. Tree rings were sorted based on their widths, and then the ring width effect on IADFs occurrence was removed by fitting a Chapman or a Weibull function. The selection of the best function was determined using the Akaike's Information Criterion (AIC) that corresponds to the lowest AIC value (Akaike 1974). According to the Chapman function, the IADF frequency increases with tree-ring width up to a maximum value and afterwards reaches a plateau, whereas the Weibull function decreases after reaching its maximum. This means that the probability of IADFs occurrence decreases for wider tree rings. Finally, the obtained IADF frequency indices were averaged into a chronology of IADFs. The resulting IADFs chronologies are considered standardized and assumed to be independent of age and size. The Spearman's correlation of all PLP and PIP standardized IADFs chronologies, between and within sites, was also calculated.

\section{Climatic data}

Monthly data of mean, minimum, and maximum air temperature ( $T_{\text {mean }}, T_{\text {min }}$ and $\left.T_{\max }\right)$ and total monthly precipitation (Pre) were retrieved from the CRU TS V.4.0 database through the Climate Explorer application (http://clime xp.knmi.nl). The gridded data were then corrected for the mean altitude of each site, using the climate software package ClimateEU v.4.63 (http://tinyurl.com/ClimateEU, Hamann et al. 2013). To assess IADFs-climate relationships, Pearson's correlations between the climatic data and the standardized IADFs chronologies, for the common period 1984-2008, were calculated. The 1984-2008 time interval was selected based on the common period, sample replication greater than four trees.

\section{Results}

\section{Tree-ring width chronologies}

The sample depth at each site ranges from 17 to 29 trees. The mean PLP tree age is 48 years, and the mean PIP tree age is 24 years (Table 2). The PLP have the highest values of first-order autocorrelation (AC1). The mean tree-ring width of PIP is lower than the PLP, as well as the range of their increments $1.25-7.5 \mathrm{~mm}$ (PIP), vs $4.30-10.6 \mathrm{~mm}$ (PLP) (Table 3). PLP radial growth curves show a clear negative trend after 1970, whereas the shorter PIP radial growth curves are relatively steady without evident age effect (Fig. 2). One of the largest PIP tree-ring width is in 2003 , followed by a narrow ring in 2004. Spearman's correlation between the PLP and PIP tree-ring width chronologies are not always significant among and within sites (Table S1). The PIP tree-ring width chronologies are significantly correlated higher with each other than the PLP chronologies with one exception (Table S1). Moreover, PIP tree-ring width chronologies are significantly correlated $(p<0.05)$ with PLP chronologies with one exception (OCR site, Table S1).

\section{IADFs frequencies and climatic signals}

Results show an increasing frequency of IADFs in PLP trees from 1970-1980 and in PIP trees from 1995-2005 (Fig. 3). In PLP, the stabilized IADFs frequency declines during the last 10-20 years, mainly at sites VET and OCR and the trend is left-skewed with a maximum peak in the juvenile phase.

The years with high-stabilized IADFs frequency are listed in Table 4. Analysis of the relationship between climatic conditions (mean monthly temperatures and total monthly precipitation) in those years with the highest stabilized IADF frequency indicates that there is a clear association with drought conditions, namely high temperatures and low
Table 2 Main features of the sampled trees at the three study sites: VET, SFR, and OCR

\begin{tabular}{llll}
\hline & VET & SFR & OCR \\
\hline PIP & & & \\
$\quad$ No. trees & 29 & 27 & 24 \\
Mean stem base diameter (cm) & $18.5( \pm 7.8)$ & $16( \pm 4.4)$ & $15( \pm 5.6)$ \\
Mean tree height (cm) & $345( \pm 178)$ & $274( \pm 99)$ & $252( \pm 111.6)$ \\
Mean cambial age (at stem base) & $24( \pm 5.3)$ & $23( \pm 6.2)$ & $24( \pm 5.9)$ \\
PLP & & & \\
No. trees & 19 & 18 & 17 \\
Mean DBH (cm) & $37.3( \pm 3.1)$ & $30.7( \pm 5.7)$ & $24.7( \pm 4.1)$ \\
Mean height (m) & $11.8( \pm 1.1)$ & $11.3( \pm 2.1)$ & $20.2( \pm 3.2)$ \\
Mean cambial age (at DBH) & $53( \pm 8.2)$ & $43( \pm 3)$ & $49( \pm 1.9)$ \\
\hline
\end{tabular}

The standard deviation in brackets $P I P$ pioneer pines, $P L P$ planted pines 
Table 3 Summary of the tree-ring chronologies statistics for planted (PLP) and pioneer (PIP) pines

\begin{tabular}{lcclllllllll}
\hline Sites & Start & End & $\begin{array}{l}\text { Mean TRW } \\
(\mathrm{mm})\end{array}$ & $\begin{array}{l}\text { Min } \\
\text { TRW } \\
(\mathrm{mm})\end{array}$ & $\begin{array}{l}\text { Max } \\
\text { TRW } \\
(\mathrm{mm})\end{array}$ & $\begin{array}{l}\text { Max TRW }(\mathrm{mm}) \\
\text { CI 1984-2008 }\end{array}$ & SD & MS & AC1 & Rbar & EPS \\
\hline VET PLP & 1951 & 2013 & 3.00 & $0.35-2.02$ & $4.47-9.0$ & $2.17-5.78$ & \pm 1.534 & 0.211 & 0.833 & 0.412 & 0.737 \\
VET PIP & 1973 & 2008 & 2.43 & $0.12-3.22$ & $1.79-7.28$ & $1.48-7.28$ & \pm 0.929 & 0.286 & 0.536 & 0.307 & 0.639 \\
SFR PLP & 1967 & 2011 & 2.96 & $0.36-1.5$ & $4.30-8.17$ & $1.52-6.72$ & \pm 1.431 & 0.223 & 0.794 & 0.581 & 0.847 \\
SFR PIP & 1978 & 2011 & 2.51 & $0.09-1.78$ & $1.25-6.57$ & $1.2-6.57$ & \pm 1.142 & 0.353 & 0.453 & 0.408 & 0.674 \\
OCR PLP & 1962 & 2012 & 2.71 & $0.21-1.09$ & $6.58-10.6$ & $1.19-4.69$ & \pm 1.910 & 0.252 & 0.857 & 0.592 & 0.813 \\
OCR PIP & 1971 & 2012 & 1.99 & $0.11-2.28$ & $1.63-7.52$ & $1.63-7.52$ & \pm 0.895 & 0.364 & 0.447 & 0.612 & 0.863 \\
\hline
\end{tabular}

Range of max, min and mean tree-ring width by tree for the entire length of each series and for the common interval 1984-2008. Rbar and EPS were calculated on detrended series for the common interval 1984-2008

$S D$ standard deviation, $M S$ mean sensitivity, $A C 1$ first-order autocorrelation, Rbar interseries correlation, EPS expressed population signals
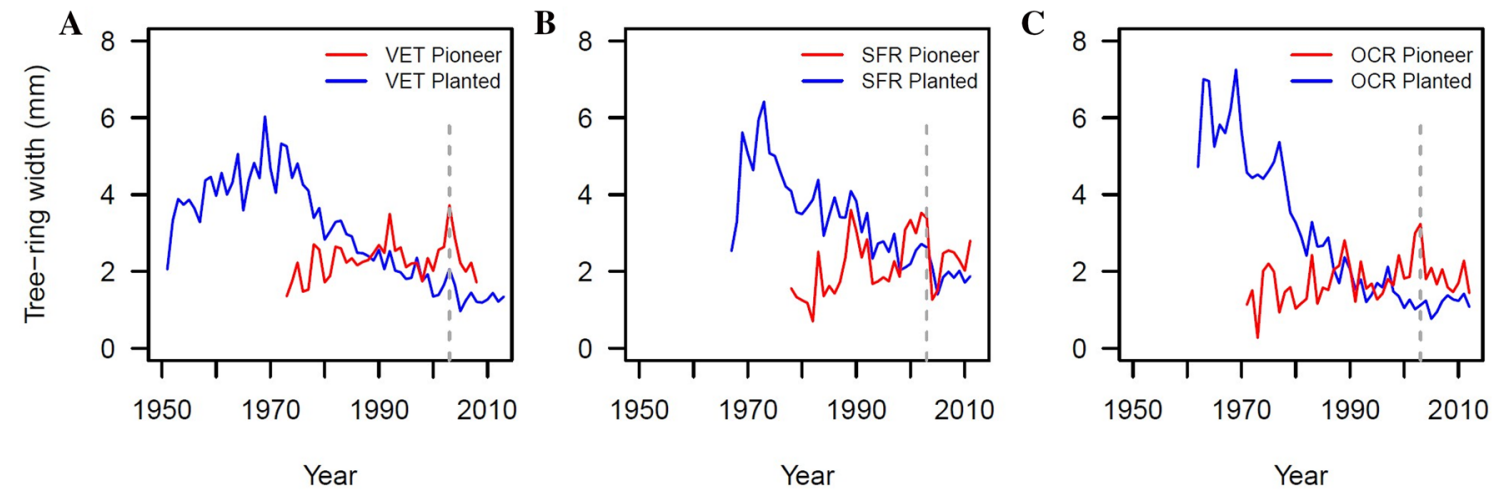

Fig. 2 Tree-ring width chronologies of pioneer (red) and planted (blue) pines at a VET, b SFR, and $\mathbf{c}$ OCR sites. The grey dashed line highlights the year 2003, a pointer year with the widest tree ring for pioneer pines
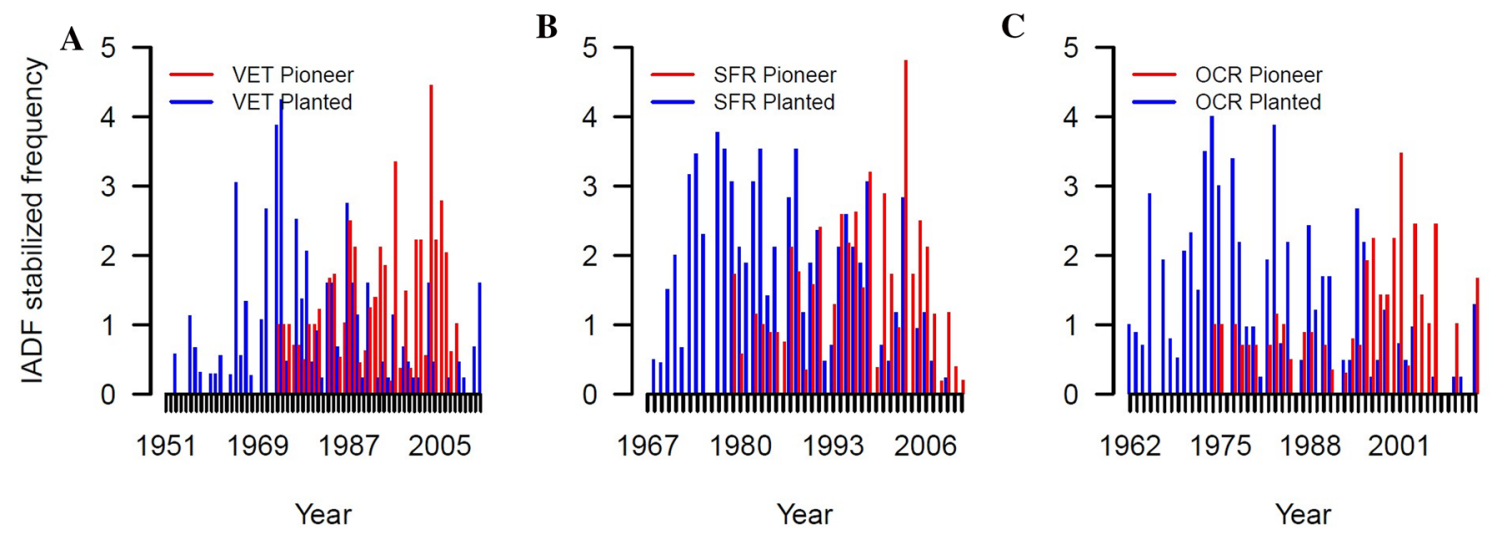

Fig. 3 Stabilized IADFs frequency of pioneer (red) and planted (blue) pines, at a VET, b SFR, and $\mathbf{c}$ OCR sites

precipitation. Amongst the PLP trees this relationship peaks in July, whereas for PIP trees the peak shift is in August (Fig. 4).

Most IADFs occurred in the latewood and are mainly of $\mathrm{L}+$ and $\mathrm{L}$ types. The frequency of IADFs in PIP and PLP, considering the different sample depths and time interval for each site, is presented in Table 5. SFR site shows the highest IADFs frequency in both PLP and PIP trees, and at VET the IADFs frequency in PIP is always higher than the PLP trees.

The relationship between standardized IADFs frequency and ring width is described by exponential curves that tend to stabilize in all cases (Chapman function) except for the 
Table 4 Years with the highest IADFs frequency (stabilized

IADFs frequency $>2.5$ standard deviation) in each site (VET, SFR, and OCR sites) and considering all planted (PLP) and all pioneer (PIP) pines

\begin{tabular}{|c|c|c|c|c|c|c|c|}
\hline \multicolumn{3}{|c|}{ Planted } & \multicolumn{3}{|c|}{ Pioneer } & \multirow[t]{2}{*}{ All PLP } & \multirow[t]{2}{*}{ All PIF } \\
\hline VET & SFR & OCR & VET & SFR & $\mathrm{OC}$ & & \\
\hline 1965 & & 1965 & 1987 & & & 1973 & 2000 \\
\hline 1971 & & & 1996 & & & 1974 & 2001 \\
\hline 1973 & 1973 & 1973 & & & 1997 & 1977 & 2003 \\
\hline \multirow[t]{2}{*}{1974} & 1974 & 1974 & & 1998 & & 1983 & \\
\hline & & 1975 & & 2000 & 2000 & 1988 & \\
\hline \multirow[t]{3}{*}{1977} & 1977 & 1977 & & & 2001 & & \\
\hline & 1978 & & 2003 & 2003 & 2003 & & \\
\hline & 1983 & 1983 & 2005 & & & & \\
\hline \multirow[t]{2}{*}{1987} & & & & & 2006 & & \\
\hline & 1988 & & & & & & \\
\hline
\end{tabular}
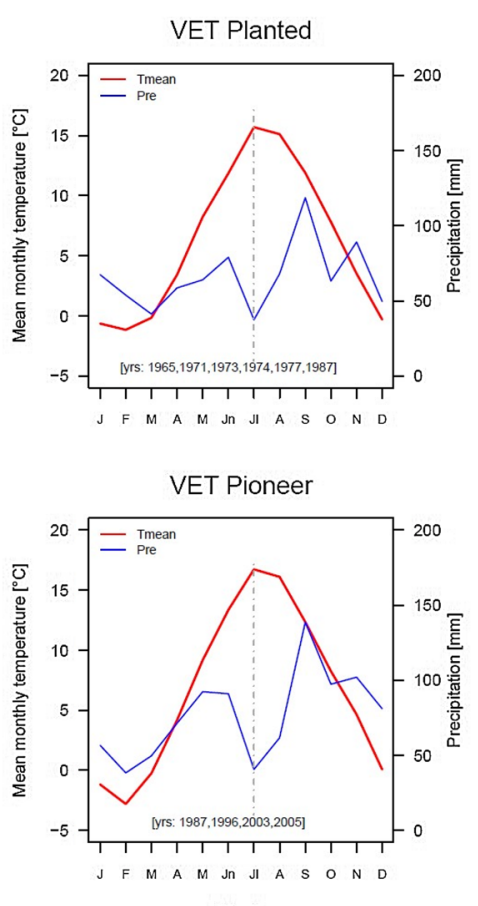

Month
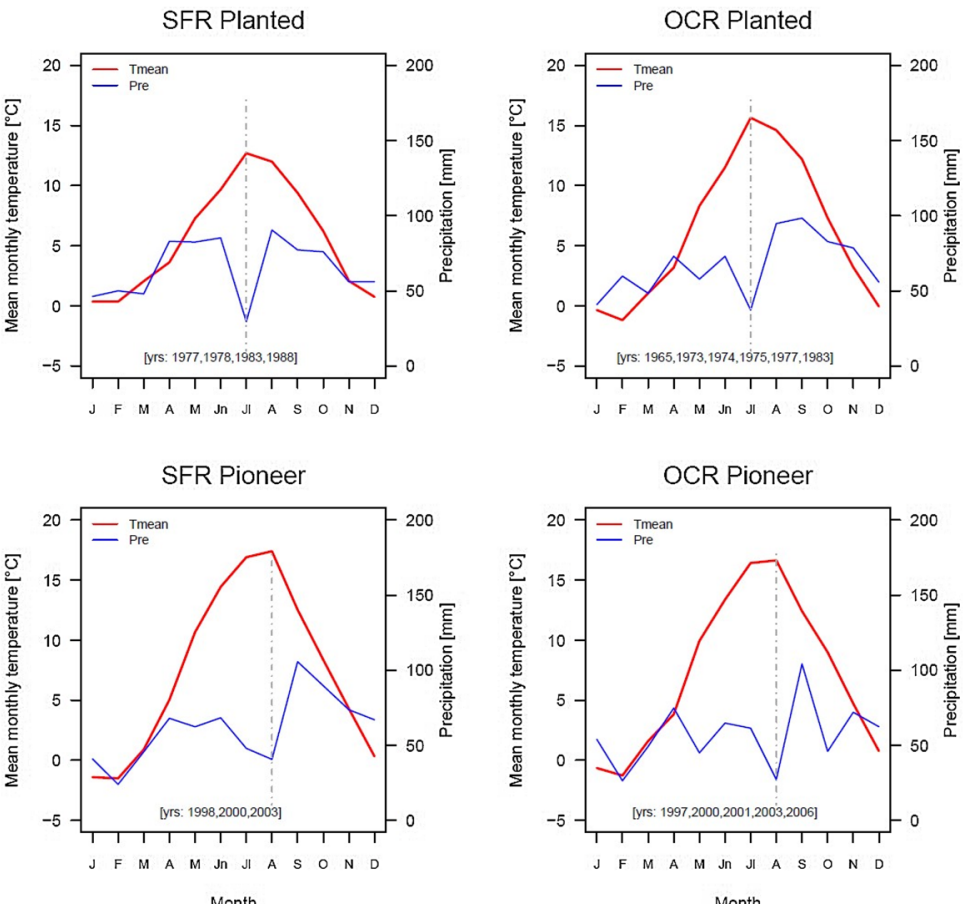

Month
Fig. 4 Trends of mean monthly temperatures (red) and total monthly precipitation (blue) for the years with highest IADFs frequencies (stabilized IADFs frequency $>2.5$ standard deviation), for planted and pioneer pines at VET, SFR, and OCR sites. The years with highest IADFs frequency are written in the brackets in each panel

Spearman's correlations of planted and pioneer pines IADFs chronologies are always significant among and within sites (Table S2). Correlation coefficients in PLP range from 0.48 to 0.58 for all pairs. PIP IADFs chronologies are significantly correlated $(p<0.05)$ with PLP IADFs chronologies at VET $(\rho=0.48, \mathrm{p}<0.05)$, SFR $(\rho=0.67$, $p<0.05)$, and OCR $(\rho=0.38, p<0.05)$ sites.

The IADFs-climate relationships do not show an overall pattern but some similarity within site, mainly in SFR (Fig. 7). 
Table 5 Frequency of IADFs latewood type ( $\mathrm{L}$ and $\mathrm{L}+$ and $\mathrm{LL}+$ ), in pioneer (PIP) and planted (PLP) pines

\begin{tabular}{lll}
\hline Sites & $\begin{array}{l}\text { PLP } \\
(\mathrm{L}, \mathrm{L}+\text { and LL+) }\end{array}$ & $\begin{array}{l}\text { PIP } \\
(\mathrm{L}, \mathrm{L}+\text { and LL+ })\end{array}$ \\
\hline $\begin{array}{l}\text { Entire time span } \\
\text { VET }\end{array}$ & \\
SFR & $20.2 \%(1951-2013)$ & $32.8 \%(1973-2008)$ \\
OCR & $40.1 \%(1967-2011)$ & $36.5 \%(1978-2011)$ \\
Common interval (1984-2008) & $26.6 \%(1984-2012)$ \\
VET & $30 \%(1962-2012)$ & \\
SFR & $14.3 \%$ & $32 \%$ \\
OCR & $34 \%$ & $40.3 \%$ \\
\hline
\end{tabular}

The analysis time intervals are for the common interval 1984-2008, and for the entire timespans (in brackets)

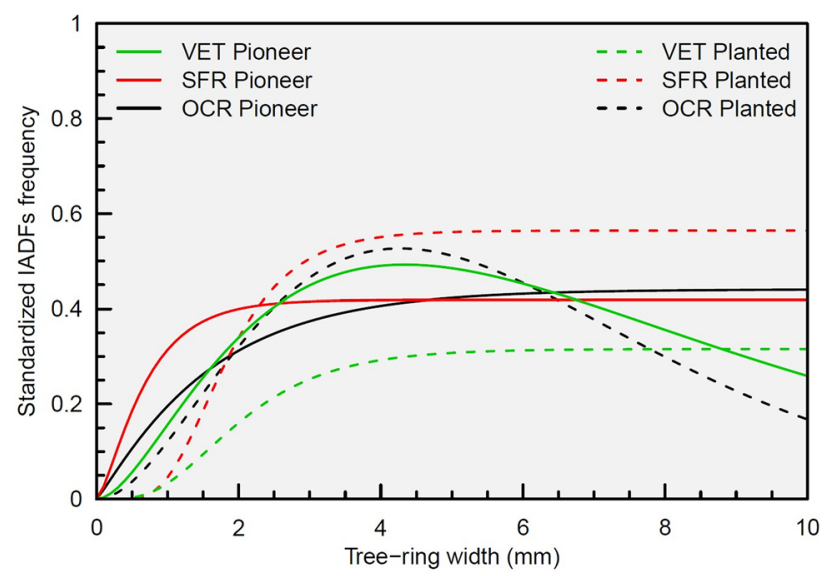

Fig. 5 Standardized IADFs frequency curves as function of tree-ring width under the Chapman and the Weibull functions for both pioneer (solid line) and planted (dashed line) pines at VET, SFR, and OCR sites

Correlations between standardized IADFs and averaging December $(t-1)-$ January $(t)$ precipitation is common at all sites in PIP. However, the strongest correlations appear between standardized IADFs and temperatures with both positive and negative effects at SFR and VET sites. In fact, a negative correlation is found with spring temperatures (average February and March $(t)$ ) in PIP, and a positive signal with July $(t)$ temperatures in PLP.

\section{Discussion}

In this study, we demonstrate how using yearly resolved IADFs frequency can provide valuable tree-climate sensitivity information from trees that would otherwise be challenging to study using traditional dendroclimatic technique due to their young age.

\section{Radial growth of pioneer and planted pines}

In the past 20-30 years, the PIP displayed a steady or even increasing trend in ring width, peaking in 2003 (Fig. 2), which in the Apennines was a growing season with high temperatures and high June precipitation (Fig. S1). This suggests that increasing temperatures with high rainfalls favours tree-ring growth at the upper forest limit by extending the growing season. In fact, the 2003 growing season was $2 \%$, $12 \%$ and $64 \%$ longer in subalpine, alpine, and nival areas respectively and induced and exceptional increase of basal area in many subalpine species in Europe (Jolly et al. 2005). After the 2003 heatwave, both pioneer and planted pines respond with an abrupt tree-ring width reduction, probably caused by a dry summer in 2004 (Fig. S1). In PLP, the drought effect lasted to 2005, the year with the narrowest ring width (Fig. S2). This can explain the high value of firstorder autocorrelation in tree-ring widths, especially for PLP trees, indicating the lag effect of previous year conditions on current growth of black pines at our sites. Moreover, despite some differences in site features (e.g. aspect and slope), the common growth pattern is revealed by high inter-series correlation coefficients (Rbar), and by high cross-correlation values between PIP and PLP tree-ring width chronologies. The only exception is the north exposed site (OCR), likely due to different growing conditions.

\section{IADFs characteristics and relationships with age and tree ring width}

Most of the IADFs are in the latewood, with the highest frequency found in the south-west exposed sites (VET and SFR). IADFs are earlywood-like cells within the latewood (L type), and earlywood-like cells between the latewood and the earlywood of the next ring ( $\mathrm{L}+$ type) (Campelo et al. 2007). The genus Pinus is prone to latewood IADFs production and their formation is triggered by high precipitation in early (L) or late (L+) autumn (e.g. Rigling et al. 2001; Masiokas and Villalba, 2004; Vieira et al. 2009; Battipaglia et al. 2010; De Luis et al. 2011; Rozas et al. 2011; Carvalho et al. 2015; Vieira et al. 2017). Nonetheless, the central Apennines are not under the typical Mediterranean bioclimatic conditions. The three sampled sites share a temperate oceanic macrobioclimate (sensu Rivas-Martinez and RivasSaenz 2009) with short drought periods in July-August and precipitation peaks in early spring and autumn. The growing season at $1600 \mathrm{~m}$ elevation extends from beginning of June to mid-late October. The transition from earlywood to latewood usually begins in August, most of the latewood cells are formed in September, and the maturation and lignification processes are completed in October (Piermattei et al. 2015). Few earlywood IADFs (type E, and E+) were found (e.g. in 1973, 1974) and only in PLP. Their formation 

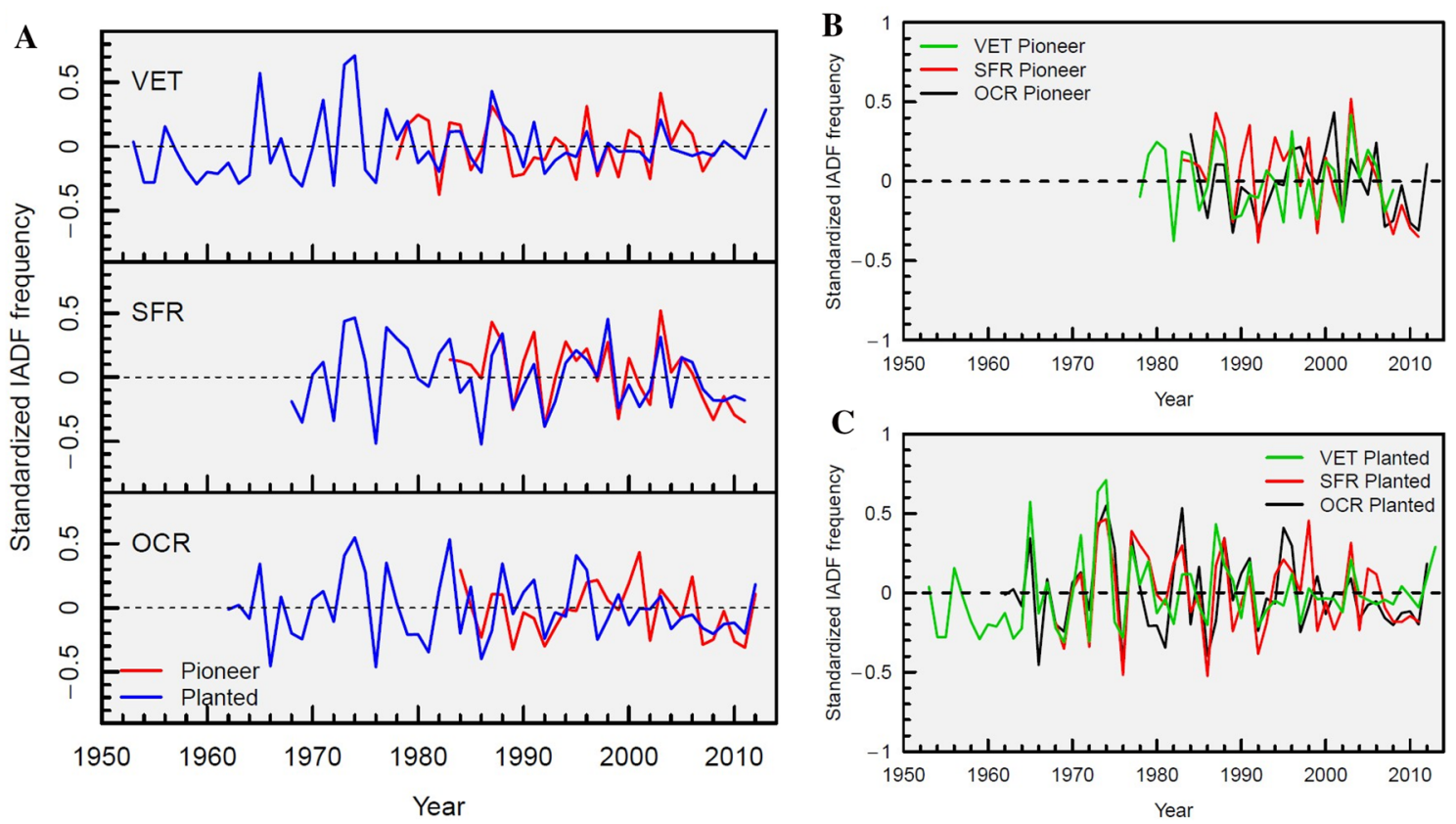

Fig. 6 Standardized IADFs chronologies (standardization with removal of age and tree-ring width effect). a A comparison of pioneer (red line) and planted (blue line) pines, $\mathbf{b}$ all pioneer pines, and $\mathbf{c}$ all planted pines

usually follows a water deficit early in the growing season (e.g., Wimmer et al. 2000; Campelo et al. 2007), a condition uncommon in the study areas where snowfalls can be abundant in late winter (February and March), and occasionally extends to May-early June (De Bellis et al. 2010).

Moreover, to investigate the effect of climate on IADFs frequency over time, we need to account for the unequal probabilities of detecting IADFs in narrow and wide rings (Rigling et al. 2001, 2002; Battipaglia et al. 2010; Campelo et al. 2013; Novak et al. 2013), and that tree-ring widths commonly decrease with age. We expect higher IADFs frequency in wider rings because more cells are under differentiation for a longer period, which makes IADF formation more likely as long as the triggering factor occurs (Campelo et al. 2015; Vieira et al. 2018). Other studies also found more IADFs in younger than in older ones (e.g., Copenheaver et al. 2006; Vieira et al. 2009, 2010). Controversially in our study, the narrowest rings occurred in younger trees. Our results confirmed the importance of age and tree-ring width on IADFs formation. In fact, besides the stabilized IADFs frequency is highly synchronized, PLP showed an increase in IADFs frequency in the year 1970-1990 with a decline in the last years that could be linked to ring width reduction, evident at VET and OCR sites. However, in narrow rings $(<2 \mathrm{~mm})$, the highest IADFs frequency occurred in PIP, whereas an IADFs frequency increase is expected in relatively wider rings $(>2 \mathrm{~mm})$, finding the IADFs frequency peak in 3-5 mm wide tree rings and in 19-38 years old trees (Zalloni et al. 2016). Our results confirm that young trees growing above the forest line, even with narrow rings, showed the formation of more IADFs possibly related to more variable growth conditions. In this study, we used a Weibull or a Chapman function to standardize the IADFs frequency from age and tree-ring width (Novak et al. 2013; Campelo et al. 2015). This revised method to standardize IADF frequency chronologies allows detecting a decrease in IADF formation probability in wider rings using the Weibull curve as it happens in VET pioneer and OCR planted pines. This may explain why IADFs are not formed in wide rings, when environmental conditions are favourable and stable throughout the growing season.

Synchronization of standardized IADF chronologies within and between study sites suggests a common IADF formation driver. Considering only the years with the highest IADFs frequency, a clear pattern emerges: a combination of low precipitation and high mean temperatures in July (August) caused the maximum IADFs occurrence in PLP (PIP) trees. Interestingly, there is a different sensitivity to drought between PIP and PLP. At high altitude, drought condition in August is the driving factor for IADFs formation. However, considering the standardized IADFsclimate relationship in the common interval 1984-2008, this result is confirmed only in PLP. The positive correlation with July temperature is probably related to a water deficit particularly at VET and SFR, respectively south and south-west exposed. Our results are consistent with those of Campelo et al. (2018) where IADFs are more frequent in south-facing slope trees, with a longer growing season. 

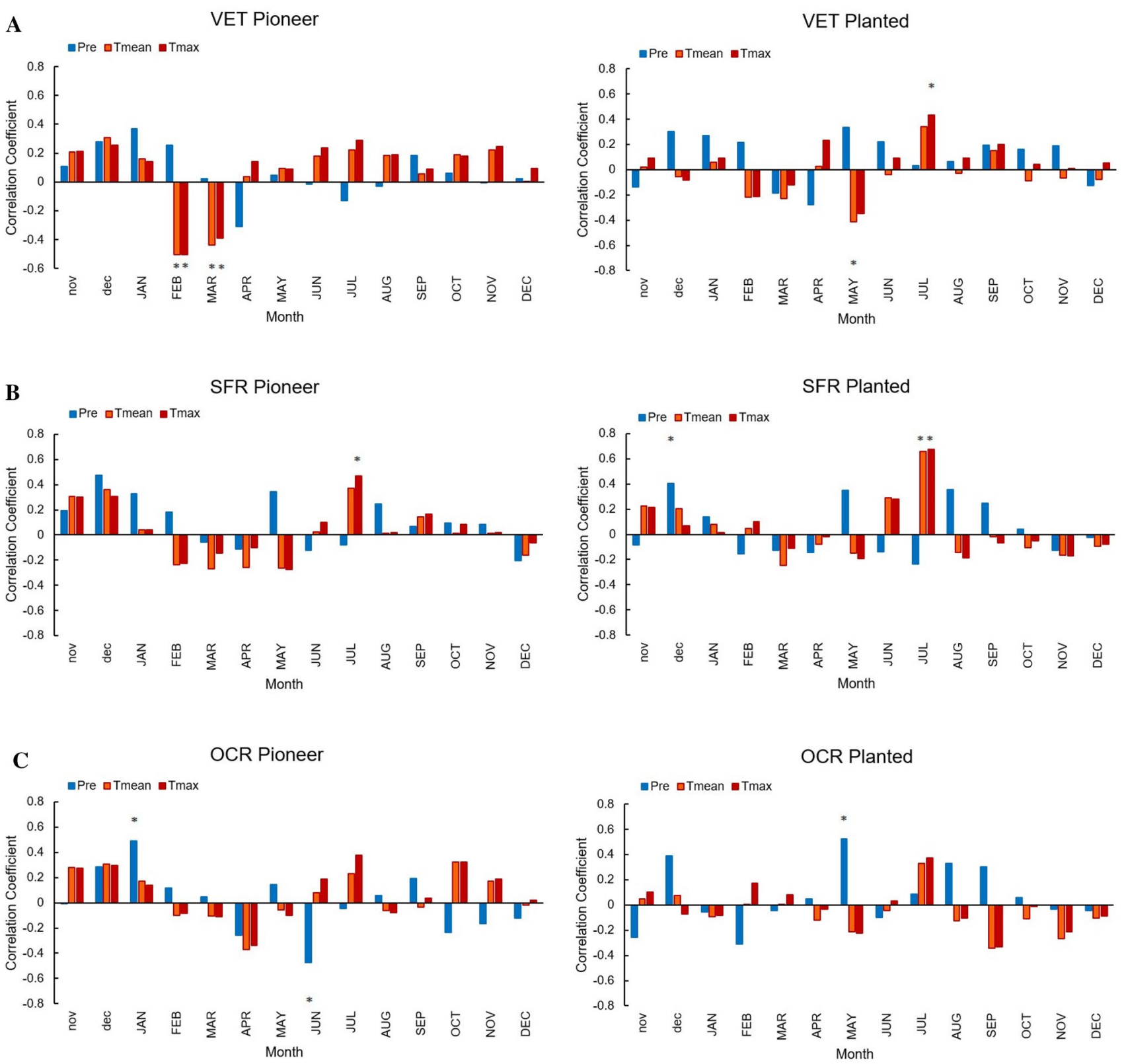

Fig. 7 Pearson's climate correlation between standardized IADFs chronologies and total monthly precipitation (Pre; blue), mean (Tmean; orange) and maximum (Tmax; red) monthly air temperatures

for the common period 1984-2008 in pioneer and planted pines at a VET, b SFR, and c OCR sites. Asterisk $(*)$ indicates significant correlation $(p<0.05)$

Instead, the low climatic sensitivity of standardized IADFs in pioneer pines might be due to a combination of precipitation, temperatures, and soil moisture, where microsite conditions play a fundamental role, highlighting a possible individual adaptation. In conclusion, with this study we want to promote the standardization method to highlight the climatic effect on IADFs chronologies that ultimately allow a better comprehension of tree responses to fluctuations in environmental conditions.

Author contribution statement $\mathrm{AP}$ and FC planned and designed the research; AP, CU, MG, and AC conducted fieldwork; AP collected the data; AP and FC analyzed the data, with substantial contribution from UB; AP led the manuscript with contributions from all authors. All authors contributed critically to the drafts and gave final approval for publication. 
Acknowledgements We would like to thank Paul J. Krusic for language revision of the manuscript text and for his valuable comments. We also wish to thank the following institutions and people for providing sampling authorisation, logistic support, and field and laboratory assistance: the Monti Sibillini National Park, the Gran Sasso-Monti della Laga National Park, the Sirente-Velino Regional Park, and Bruno Petriccione, Francesco Renzaglia, Valeria Gallucci, Emidia Santini, Luca Bagnara, Matteo Giove, Andrea Cola, Simone Cingolani, Marco Altieri, Alessandro Vitali, and Edoardo Piermattei. We would also like to thank Giada Centenaro for assistance in preparing Fig. 1. This research was partly funded by Marche Polytechnic University grants.

Open Access This article is licensed under a Creative Commons Attribution 4.0 International License, which permits use, sharing, adaptation, distribution and reproduction in any medium or format, as long as you give appropriate credit to the original author(s) and the source, provide a link to the Creative Commons licence, and indicate if changes were made. The images or other third party material in this article are included in the article's Creative Commons licence, unless indicated otherwise in a credit line to the material. If material is not included in the article's Creative Commons licence and your intended use is not permitted by statutory regulation or exceeds the permitted use, you will need to obtain permission directly from the copyright holder. To view a copy of this licence, visit http://creativecommons.org/licenses/by/4.0/.

\section{References}

Adams HR, Barnard HR, Loomis AK (2014) Topography alters tree growth-climate relationships in a semi-arid forested catchment. Ecosphere 5(11):1-16

Akaike H (1974) A new look at the statistical model identification. IEEE Trans Automat Control AC 19:716-723

Battipaglia G, De Micco V, Brand WA, Linke P, Aronne G, Saurer M, Cherubini P (2010) Variations of vessel diameter and d13Cin false rings of Arbutus unedo L. reflect different environmental conditions. New Phytol 188:1099-1112

Battipaglia G, Campelo F, Vieira J, Grabner M, De Micco V, Nabais C, Cherubini P, Carrer M, Bräuning A, Čufar K, Di Filippo A, García-González I, Koprowski M, Klisz M, Kirdyanov AV, Zafirov N, De Luis M (2016) Structure and function of intra-annual density fluctuations: mind the gaps. Front Plant Sci 7:595

Björklund J, Seftigen K, Schweingruber F, Fonti P, von Arx G, Bryukhanova MV, Cuny HE, Carrer M, Castagneri D, Frank DC (2017) Cell size and wall dimensions drive distinct variability of earlywood and latewood density in Northern Hemisphere conifers. New Phytol 216:728-740

Bogino SM, Bravo F (2009) Climate and intra-annual density fluctuations in Pinus pinaster subsp. mesogeensis in Spanish woodlands. Can J For Res 39:1557-1565

Bräuning A (1999) Dendroclimatological potential of drought-sensitive tree stands in southern Tibet for the reconstruction of monsoonal activity. IAWA J 20:325-338

Bunn A (2008) A dendrochronology program library in R (dplR). Dendrochronologia 26:115-124

Campelo F, Nabais C, Freitas H, Gutierrez E (2007) Climatic significance of tree-ring width and intra-annual density fluctuations in Pinus pinea from a dry Mediterranean area in Portugal. Ann For Sci 64:229-238

Campelo F, García-González I, Nabais C (2012) detrendeR-a graphical user interface to process and visualize tree-ring data using R. Dendrochronologia 20:57-60
Campelo F, Vieira J, Nabais C (2013) Tree-ring growth and intraannual density fluctuations of Pinus pinaster responses to climate: does size matter? Trees 27:763-772

Campelo F, Vieira J, Battipaglia G, De Luis M, Nabais C, Freitas $\mathrm{H}$, Cherubini $\mathrm{P}$ (2015) Which matters most for the formation of intra-annual density fluctuations in Pinus pinaster: age or size? Trees 29:237-245

Campelo F, Gutiérrez E, Ribas M, Sánchez-Salguero R, Nabais C, Camarero JJ (2018) The facultative bimodal growth pattern in Quercus ilex - A simple model to predict sub-seasonal and inter-annual growth. Dendrochronologia 49:77-88. doi:https:// doi.org/10.1016/j.dendro.2018.03.001

Carvalho A, Nabais C, Vieira J, Rossi S, Campelo F (2015) Plastic Response of Tracheids in Pinus pinaster in a Water-Limited Environment: Adjusting Lumen Size instead of Wall Thickness. PLoS One 10(8):e0136305

Copenheaver CA, Pokorski EA, Currie JE, Abrams MD (2006) Causation of false ring formation in Pinus banksiana: a comparison of age, canopy class, climate and growth rate. For Ecol Manage 236:348-355

De Bellis A, Pavan V, Levizzani V (2010) Climatologia e variabilità interannuale della neve sull'Appennino Emiliano Romagnolo. Quaderno Tecnico ARPA-SIMC n. 19

De Luis M, Gričar J, Čufar K, Raventós J (2007) Seasonal dynamics of wood formation in Pinus halepensis from dry and semi-arid ecosystems in Spain. IAWA J 28:389-404

De Luis M, Novak K, Raventós J, Gricar J, Prislan P, Čufar K (2011) Climate factors promoting intra-annual density fluctuations in Aleppo pine (Pinus halepensis) from semiarid sites. Dendrochronologia 29:163-169

De Micco V, Battipaglia G, Cherubini P, Aronne G (2014) Comparing methods to analyse anatomical features of tree rings with and without intra-annual density fluctuations (IADFs). Dendrochronologia 32(1):1-6

Esper J, Schneider L, Smerdon JE, Schöne BR, Büntgen U (2015) Signals and memory in tree-ring width and density data. Dendrochronologia 35:62-70

Fritts HC (2001) Tree rings and climate. The Blackburn Press, Caldwell

Hamann A, Wang T, Spittlehouse DL, Murdock TQ (2013) A comprehensive, high-resolution database of historical and projected climate surfaces for western North America. Bull Am Meteor Soc 94:1307-1309

Holmes RL (1983) Computer-assisted quality control in tree-ring dating and measurement. Tree Ring Bulletin 43:69-78

Jolly WM, Dobbertin M, Zimmermann NE, Reichstein M (2005) Divergent vegetation growth responses to the 2003 heat wave in the Swiss Alps. Geophys Res Lett 32:L18409

Klisz M, Koprowski M, Ukalska J, Nabais C (2016) Does the genotype have a significant effect on the formation of intra-annual density fluctuations? A case study using Larix decidua from northern Poland. Front. Plant Sci 7

Masiokas M, Villalba R (2004) Climatic significance of intra-annual bands in the wood of Nothofagus pumilio in southern Patagonia. Trees 18:696-704

Novak K, Saz-Sánchez MA, Čufar K, Raventós J, De Luis M (2013) Age, climate and intra- annual density fluctuations in Pinus halepensis in Spain. IAWA J 34:459-474

Olano JM, Eugenio M, Carcia-Cervigon AI, Folch M, Rozas V (2012) Quantitative tracheid anatomy reveals a complex environmental control of wood structure in continental Mediterranean climate. Int J Plant Sci 173:137-149

Osborn TJ, Briffa KR, Jones PD (1997) Adjusting variance for samplesize in tree-ring chronologies and other regional mean time series. Dendrochronologia 15:1-10 
Piermattei A, Garbarino M, Urbinati C (2014) Structural attributes, tree-ring growth and climate sensitivity of Pinus nigra Arn. at high altitude: common patterns of a possible treeline shift in the central Apennines (Italy). Dendrochronologia 32:210-219

Piermattei A, Crivellaro A, Carrer M, Urbinati C (2015) The "blue ring": anatomy and formation hypothesis of a new tree-ring anomaly in conifers. Trees 29(2):613-620

Piermattei A, Lingua E, Urbinati C, Garbarino M (2016) Pinus nigra anthropogenic treelines in the central Apennines show common pattern of tree recruitment. Eur J For Res 135:1119-1130

Rigling A, Waldner PO, Forster T, Bräker OU, Pouttu A (2001) Ecological interpretation of tree-ring width and intra-annual density fluctuations in Pinus sylvestris on dry sites in the central Alps and Siberia. Can J For Res 31:18-31

Rigling A, Bräker O, Schneiter G, Schweingruber FH (2002) Intraannual tree- ring parameters indicating differences in drought stress of Pinus sylvestris forests within the Erico-Pinion in the Valais (Switzerland). Plant Ecol 163(1):105-121

Rivas-Martinez and Rivas-Saenz (2009) Worldwide bioclimatic classification system, 1996-2015. Phytosociological Research Center, Spain. http://www.globalbioclimatics.org

Rozas V, Garcia-Gonzalez I, Zas R (2011) Climatic control of intraannual wood density fluctuations of Pinus pinaster in NW Spain. Trees 25:443-453

Sheppard PR (2010) Dendroclimatology: extracting climate from trees. Wiley Interdiscip Rev Clim Change 1:343-352

Vieira J, Campelo F, Nabais C (2010) Intra-annual density fluctuations of Pinus pinaster are a record of climatic changes in the western Mediterranean region. Can J For Res 40:1567-1575

Vieira J, Campelo F, Nabais C (2009) Age-dependent responses of tree-ring growth and intra-annual density fluctuations of Pinus pinaster to Mediterranean climate. Trees 23:257-265
Vieira J, Carvalho A, Campelo F (2018) Xylogenesis in the early life stages of maritime pine. For Ecol Manage 428. https://doi. org/10.1016/j.foreco.2018.04.037

Vieira J, Nabais C, Rossi S, Carvalho A, Freitas H, Campelo F (2017) Rain exclusion affects cambial activity in adult maritime pines. Agric For Meteorol 237-238:303-310

Vitali A, Camarero JJ, Garbarino M, Piermattei A, Urbinati C (2017) Deconstructing human-shaped treelines: Microsite topography and distance to seed source control Pinus nigra colonization of treeless areas in the Italian Apennines. For Ecol Manage 406:37-45

Wigley TML, Briffa KR, Jones PD (1984) On the average value of correlated time series, with applications in dendroclimatology and hydrometeorology. J Clim Appl Meteorol 23:201-213

Wimmer R, Strumia G, Holawe F (2000) Use of false rings in Austrian pine to reconstruct early growing season precipitation. Can J For Res 30:1691-1697

Zalloni E, De Luis M, Campelo F, Novak K, De Micco V, Filippo A, Vieira J, Nabais C, Rozas V, Battipaglia G (2016) Climatic signals from intra-annual density fluctuations frequency in Mediterranean Pines at a regional scale. Front Plant Sci 7:1-11

Publisher's Note Springer Nature remains neutral with regard to jurisdictional claims in published maps and institutional affiliations. 